\title{
The causes and implications of obstetric malpractice
}

\author{
Puteri Nemie Jahn Kassim $^{1}$, Khadijah Mohd Najid ${ }^{2}$ \\ ${ }^{1}$ Professor, Civil Law Department, Ahmad Ibrahim Kulliyyah of Laws,International Islamic University Malaysia \\ ${ }^{2}$ Doctor of Philosophy in Law (PhD in Law) Student, Ahmad Ibrahim Kulliyyah of Laws, International Islamic University Malaysia \\ *Corresponding author E-mail: puterinemie@hotmail.com
}

Copyright $\odot 2015$ Puteri Nemie Jahn Kassim, Khadijah Mohd Najid. This is an open access article distributed under the Creative Commons Attribution License, which permits unrestricted use, distribution, and reproduction in any medium, provided the original work is properly cited.

\begin{abstract}
Obstetrics and Gynaecology $(\mathrm{O} \& \mathrm{G})$ are among the specialties at high risk of malpractice claims. In particular, obstetric malpractice attracts high incidence of claims as birth injuries are usually serious and devastating. The resulting disabilities and malformation from the injuries tend to be life-long and victims are deprived of years of enjoyment in life, independence and productivity. As these injuries occur on the victims early in life, the costs of medical care are usually enormous. As this imposes stressful and heavy burden on the family members, they tend to resort to litigation as means of procuring monetary compensation. The highest numbers of medical negligence cases in Malaysia involve obstetric injuries and six to seven-figure court awards are now becoming the trend for compensating obstetric malpractice victims. However, proving obstetric malpractice is not an easy task with years of litigation, which eventually may not provide victims with monetary compensation if unsuccessful. Further, the increase in obstetric litigation has triggered higher premium for medical indemnity insurance causing many doctors to leave the subspecialty. Even though the doctor at the end may not be found guilty but the trauma of being sued caused them to suffer difficulties in returning to their work.
\end{abstract}

Keywords: Obstetric Malpractice; Causes; Implications; Compensation; Litigation Problems.

\section{Introduction}

Obstetrics and gynaecology $(\mathrm{O} \& \mathrm{G})$ are a subspecialty concerning the delivery of medical and surgical care to women. This field is a combination of two specialties: "obstetrics, which focuses on the care of women before, during, and after childbirth; and gynaecology, which involves the diagnosis and treatment of disorders of the female reproductive system, breasts, and associated disorders" [1]. Obstetrics, in particular, is a unique field amongst several other branches of medicine as it involves pregnancies and childbirth, occasions considered to be the most intimate and joyful occasion in a patient's life. Patients often expect that their obstetric journey would end in the birth of a perfect baby and the mother in equally good health [2]. Nevertheless, despite being a natural process, severe complications can occur during childbirth, requiring prompt and accurate response by the obstetrician in charge. A single mistake albeit a simple one could immediately change a happy occasion into a devastating one, not only to the life of the expecting parents, but also to the career of the obstetrician. Obstetric injuries tend to be severe, often permanent and emotionally overwhelming, which. Consequently, triggers many years of court litigation with high amount of monetary compensation.

\section{Materials and methods}

The research has employed qualitative research method namely, Content Analysis, which covers a review of the relevant literature on issues relevant to obstetric malpractice. Primary sources include case laws while secondary sources include reviews on textbooks, journals, newspaper articles, and periodicals. 


\section{Results}

The inherent difficulties in establishing obstetric malpractice and the hazards of litigation have triggered the move to find alternative methods in compensating for birth injuries. The implementation of a no-fault compensation scheme specifically for birth-related injuries has been viewed as a viable alternative to litigation as it is able to lessen the blame culture and offer speedier compensation to injured victims in a less adversarial manner. Carving out birth injuries from the operation of tort stabilizes the insurance market thus provide practical solution to the medical insurance problem and redress to its consequential problem, including the declining number of practicing obstetricians and the rising cost of obstetrical care as a whole. Such scheme also promotes a healthier relationship between patients and obstetric provider and to some extent lessen the incident of "defensive obstetric".

\section{Discussions}

Obstetrical Malpractice occurs when harm is caused to the mother or newborn due to negligent conduct of the medical practitioner/obstetrician anytime from the early stage of prenatal course, through labor and delivery, and during the immediate aftercare of delivery (neonatal). Obstetric malpractice can occur in many settings, from mistakes made by medical staff in the maternity ward to inadequate medical care in the labour room and the mismanagement of the hospital itself throughout the whole birthing process. Obstetrical malpractice does not implicate only the obstetricians, but all medical personnel and the hospital providing obstetric care. Obstetrical malpractice is known for its high percentage of claim and large compensation awards, especially when the resulting injury is lifelong and permanent. For the purpose of the paper, discussions on obstetric malpractice will be narrowed down to "complaints brought against medical practitioners and hospitals alleging that an infant has sustained a brain injury resulting in, for example, cerebral palsy, epilepsy, or mental retardation, from alleged actions or omissions of the practitioners involved in the prenatal and perinatal care of the mother and infant" [3] or more popularly known as the "bad baby lawsuit" [3].

\subsection{Types of obstetric malpractice}

According To Crico Strategies' 2010 Annual Benchmarking Report: Malpractice Risks in Obstetrics, [4] the most frequent obstetrical malpractice case types are birth asphyxia, which accounts for $27 \%$ of obstetric malpractice cases, shoulder dystocia 18\%, intrauterine fetal death 6\%, and maternal hemorrhage 4\% [4]. Meanwhile, data from a survey conducted by the American Congress of Obstetricians and Gynecologists (ACOG) in 2012[5] reveals that the leading primary allegation for obstetric claims was for "neurologically impaired infant," which accounts for $29 \%$ of all obstetric claims. Stillbirth or neonatal death comes in second place as the most frequent primary obstetrical claim (14\%)[5]. According to the same survey, among the leading associated primary factors in obstetric claims were electronic fetal monitoring (21\%) and shoulder dystocia/brachial plexus injury (15\%) [5].

\section{a) Birth asphyxia}

Asphyxia, in simple words, means lack of oxygen [6]. Birth asphyxia or perinatal asphyxia refers to a condition "when a baby's brain and other organs do not get enough oxygen before, during or right after birth" [6]. Asphyxiated babies are born limp, pale, and do not respond to normal resuscitative efforts [7]. The degree of harm to the asphyxiated babies depends on how long and how severe the period of asphyxia is, and how quickly the right treatment is given [6]. If mild asphyxiated babies are given immediate and accurate treatment, they may stand a chance to recover [6]. For those experiencing longer deprivations of oxygen may suffer from permanent damage to their brain, heart, lungs, kidneys, bowels or other organs and may also result in stillbirth or neonatal deaths [8], [9].They may also suffer neurological disabilities and malformations such as cerebral palsy, mental retardation, nerve deficits, hearing and vision impairment [10]. Birth asphyxia may result from several causes; some are unavoidable and some are due to faulty medical care and failure by the obstetrical team to react to asphyxiated babies in a correct and timely fashion[11].

\section{b) Shoulder dystocia}

Shoulder dystocia is defined as "a vaginal cephalic delivery that requires additional obstetric maneuvers to deliver the fetus after the head has delivered, and gentle traction has failed" [12]. It is an injury which occurs when the newborn's shoulder is stuck at the birth canal during a vaginal delivery, which requires swift and appropriate obstetric manoeuvers and proper neonatal aftercare by the obstetrical team handling the delivery, failing of which would result in injuries both to the mother (postpartum haemorrhage, perineal tears, vaginal lacerations, cervical tears, bladder rupture, uterine rupture, symphyseal separation, sacroiliac joint dislocation and lateral femoral cutaneous neuropathy) [12] and the newborn (Brachial Plexus injury (BPI), fractures of the humerus and clavicle, pneumothoraces and hypoxic brain damage) [12]. Brachial Plexus injury (BPI) is regarded as one of the most common serious fetal complications of shoulder dystocia, where the nerves in the baby's neck, known as the brachial Plexus which control the function of the arm and hand are temporarily or permanently damaged, causing significant and lifelong disability [13]. Shoulder dystocia with BPI is the most common cause for litigation related to shouldering dystocia and is the second or third as the most common type of obstetric litigation [2]. NHS Litigation Authority (NHSLA) reported that $46 \%$ of such injuries were associated with substandard care" [12]. 


\section{c) Cerebral Palsy and neurological impairment}

Neurological impairment is one of the most feared consequences of Obstetric malpractice, and one, which attracts largest compensation awards. "Neurological impairment" is a general term describing "any problems stemming from damage to the brain which affect control of motor function, learning ability, and other neurologic functions" [14]. Examples of such problems may include epilepsy or seizures, mental retardation, various learning disabilities and cerebral palsy. Cerebral Palsy is an "'umbrella" term for disorders of movements and posture, resulting in limitations of activity due to non-progressive disturbances that occurred in the developing brain" [15]. Neurological impairment and cerebral palsy are often associated with events before or during birth, particularly the occurrence of birth asphyxia or/and fetal distress. Other factors include "prematurity, intrauterine infection, fetal coagulation disorders, multiple pregnancy, antepartum haemorrhage, breech presentation and chromosomal or congenital abnormalities" [16]. Symptoms of cerebral palsy are different from an individual to another and might change as children and their nervous systems mature. While some children with mild cerebral palsy display only slight awkwardness without the need for special assistance, some others with severe cases of cerebral palsy are completely disabled and require lifelong care and assistance [17]. Those requiring lifelong care tend to sue the obstetrical care provider for the future costs of care [18]. Hence, claims alleging birth-related neurological impairment and cerebral palsy account for almost one-third of all obstetric malpractice claims and result in the largest damage awards by the courts [19].

\subsection{Causes for obstetric malpractice}

There are several causes that could lead to obstetric malpractice. Among them are as follows:

\section{a) Ineffective communication and co-operation between the obstetrical team consisting of multi high-risk specialty}

Obstetrics is a unique specialty which involves multi-professional from multi-disciplinary expertise working together as a team [2]. An obstetrical team may comprise of not only the obstetrician, but also the anesthesiologist, the perinatologist, the neonatologist, the pediatrician, the midwives, the nurses, and all the medical staff involving directly or indirectly with the delivery process. A successful obstetrical procedure consists of these individuals from multidisciplinary expertise working together and assisting each other as a team. Childbirth, despite being a natural process, has the tendency to insidiously devolve into crisis where severe complications occur with little warning and requiring prompt response. Thus, "accurate interpretation, structured communication, and shared decision making leading to timely and effective intervention are paramount" [4]. Ineffective communications and lack of collaborative discussions between team members are often cited as reasons causing failure of the team to identify fetal distress and accordingly act in a timely fashion [4].

\section{b) The increased usage of advanced perinatal technology}

The increased use of advanced perinatal technology in hospitals is another factor alleged to contribute to the increasing risk of obstetric mistakes and misjudgments leading to obstetric malpractice. Current obstetric practices rely heavily on technology, which adversely may create as many problems as it may prevent. High-risk pregnancies may legitimately justify the use of advanced perinatal technologies in one sense, but problems arise when technology intervention is rushed into use even in low-risk routine pregnancies, and applied imprudently to all patients without consideration of individual needs [20], [4]. For example, it was argued that the routine use of IV and fetal monitoring devices limits the mobility of the mother, causing difficulties for the fetus to move down the birth canal, and subsequently stall or prolong labour [4]. The same also hinders the baby from positioning itself in a normal position for labor and thus, increase the risk of caesarean section or forceps delivery [4].

c) Improper management of prenatal and postnatal care

Obstetrical care outside the labour room is essential in ensuring a smooth obstetrical journey for the patient and the medical team in charge. Mismanagement of such would lead to risk of complications during labour and injury to both mother and child, therefore, exposing the entire medical team to the threat of obstetric malpractice litigation. "Malpractice cases are, in fact, rarely prompted by a single act or omission by one individual. Instead, they typically reflect a series of missteps and mishandled decisions by a team of physicians and nurses who subtly converged too late for remedy" [4]. Examples of substandard care during prenatal stage are failure to obtain relevant clinical history of the patient in determining pre-existing risk of complications, failure to recognize and identify any risks or complications developing throughout pregnancy and order appropriate antenatal test, failure to properly interpret test results or diagnose the existence of risk and recommend or initiate necessary treatment to manage complications [21]. These failures, either singularly or in combination may lead to complications which are too late to remedy, causing injury to either the mother or the baby or both. This consequently triggers obstetric malpractice litigation [2].

\section{d) Substandard care during labour/ intrapartum period}

The majority of obstetric malpractice claims cite substandard care and misstep judgments during the active stage of labour or the intrapartum period [4].The transit through the passage of the birth canal is known to be the most dangerous journey undertaken by a human being. "The fetus travels a distance of about $30 \mathrm{~cm}$ during labour and, paradoxically, the highest obstetric claims arise due to events going wrong during this very short journey" [2]. Mismanagement during labour was cited as the most common type of obstetric malpractice within ten years of obstetric claims study by NHS Litigation Study [22].The main allegation of substandard care during this period is delay [2]. In a study involving 177 
Swedish children with severe labour-related asphyxia, it was found that negligence in fetal surveillance occurred in $98 \%$ of the pregnancies, and failure to act in a timely fashion on abnormal cardiotocograph (CTG) ensued in another $71 \%$ of the pregnancies [23].Another review of 110 cases of obstetric litigation for cerebral palsy concluded that $70 \%$ of claims also concerns abnormalities of the CTG and its interpretation [2].Poor clinical decision in time of emergencies or inadequate technical skill to handle complications during labour is another factor leading to obstetric malpractice litigation [4].

\section{e) Poor communication and relationship between patient and doctor/obstetric staff}

Successful medical care depends heavily on a sound relationship and effective communication between the patient seeking medical care and the doctor as the provider of medical care. As patient autonomy gains momentum, it is crucial that communication between patient-obstetrician/doctor remains effective and unambiguous. Patient has to be wellinformed about the condition of her pregnancy and any risks of complication that may occur in order to make an informed decision to the available treatment [21]. A number of obstetric malpractice litigation are based on allegations that the patients relied on inadequate information in consenting or declining to a particular treatment. Examples of such are situations where patients claim that they were not fully informed of the possible risk of a complication in their pregnancy thus consented to vaginal birth oblivious to the existence of such risk or was not given the option of caesarean section following such risk [21]. Research conducted to obstetric patients from University of California reveals that positive doctor-patient relationship increase patient's perception of the doctor's competence, decrease their perception of the doctor's responsibility for an adverse medical outcome, and reduce their intention to file malpractice claims against both the doctor and the hospital [24].

\subsection{Implications of obstetric malpractice}

Obstetric malpractice is often quoted as the most frequent and most expensive type of medical-malpractice litigation. This is due to the nature of obstetric injuries, which tend to be serious and long-lasting, because they occur early in life and the victims have to live with their disabilities for many years to come. Children with obstetric injury will most of the times need "expensive, comprehensive medical care and often require lifelong care and assistance" [16], thus imposing a substantial financial and emotional burden on the family of the afflicted child, prompting them to initiate obstetric malpractice litigation, mostly to reduce the financial burden [16] and at the same time alleviate the emotional pain associated with the incident [2]. Obstetric injuries also deprive victims of good quality of life, as most obstetric injuries are permanent and without cure. The expensive cost of caring for a disabled child puts tremendous burden on the affected families proved to be detrimental to both their physical and psychological well-being. While some of these financial costs were previously supported through public funds via institutionalization, the growing trend of deinstitutionalization had resulted in the majority of the disabled children being cared for at home with their families [25]. A study by the United States' Centers for Disease Prevention, and Control (CDC) reveals that average lifetime costs per person were estimated at $\$ 1,014,000$ for persons with mental retardation, $\$ 921,000$ for persons with cerebral palsy, \$383,000 for persons with hearing loss, and \$601,000 for persons in vision impairment," [26] an amount in which does not include out-of-pocket expenditures, emergency room visits, lost wages of family members caring for those with the disability, and psychosocial effects. Caring for a child with disability as a result of obstetric injuries had also taken an emotional, physical and psychological toll on the family, [27], [28] especially the mother of the inflicted child [29], [30]. The frequency of obstetric malpractice and injuries had also affected the community at large whereby part of the cost of caring for a child inflicted with obstetric injury is assumed by the community through institutions, government bodies, community-based and charity organizations dedicated to provide support for the welfare of children with disabilities. Report by the United States' Centers for Disease Prevention and Control (CDC) demonstrates that the financial cost assumed by the nation "are expected to total $\$ 51.2$ billion for persons born in 2000 with mental retardation, \$11.5 billion for persons with cerebral palsy, \$1.9 billion for persons with hearing loss, and \$2.6 billion for persons with vision impairment" [26]. Frequency of medical-malpractice suits and the amount of awards against doctors can lead to sharp increases in the cost of doctor's liability insurance. Insurance companies regard the field of Obstetrics as a high-risk specialty thus increased the premiums to cater for the expensive possible malpractice suit, which in turn caused many obstetricians leaving practice leading to reduced availability of Obstetric care. Wenstein (2009) observed that; "a 2006 American College of Obstetrics and Gynecology survey showed 70\% of OB-GYNs have made changes in their practice because of lack of available or affordable medical liability insurance, and $65 \%$ have made changes because of risk or fear of liability claims or litigation. The average age at which physicians stopped practicing obstetrics is now 48, an age once considered near the midpoint of an OB-GYN's professional career" [31].

\section{Conclusion}

Obstetric injuries, specifically brain-damaged baby cases involving neurological injury and Cerebral Palsy were singled out from the operation of tort in certain countries, in an effort to respond to the crisis of malpractice insurance. This effort is made due to growing concerns among policymakers about the future availability of liability insurance, as insurance companies collapsed due to the high frequency and expensive cost of obstetric malpractice cases, and 
consequently, the future availability of obstetric services if fed-up obstetricians were to cease practice in obstetrics due to the lack of available and affordable liability insurance. They were also concerned about the rising cost of obstetric services, as to cover for the rising cost of insurance, obstetric practitioners had to pass on these cost to their patients. "Society, therefore, bears the ultimate burden of our inefficient and costly tort system through higher medical costs and a reduced number of health care providers" [32]. Obstetrics are also one of the fields of medicine, which are highly affected by defensive medicine, particularly attributable to Obstetricians' fear of litigation as it is proven to be detrimental to their career. This practice of "defensive obstetrics" had led some obstetricians to ignore their medical prudence and knowledge thus undertake an unnecessary procedure which is not in the best interest of their patients, while some other chose to refuse high-risk patients despite being well-versed in the area, both due to their fear of being sued for obstetric malpractice. The American College of Obstetricians and Gynecologists (ACOG) does periodic surveys of its members on professional liability issues, including the practice of defensive medicine. In ACOG (2012), when asked whether ob-gyns had made any practice changes since January 2009 as a result of the risk or fear of professional liability claims or litigation, "of the 9,006 responses, 57.9\% reported having made one or more changes to their practice" [33], of which " $27.4 \%$ decreased the number of high-risk obstetric patients; $23.8 \%$ reported increasing the number of cesarean deliveries, and $18.9 \%$ stopped offering and performing VBACs. An additional $11.5 \%$ decreased the number of total deliveries, and 6.2\% stopped practicing obstetrics altogether" [33]. Defensive Obstetrics which comprises of undertaking unnecessary procedures have the effect of contributing to the increasing cost of Obstetric care, as these unnecessary procedures involves the use of machineries such as Electric Fetal Monitoring despite inconclusive data regarding the benefits of such electronic monitoring [32] and additional time and energy spent unnecessarily on the patient. Some procedures were also undertaken for the sake of reducing the possibility of litigation without regard to the best interest of the patient, such as unnecessary caesarean section despite knowing that it is best that deliveries took place being as natural as possible. Kim (2007) observed; "Many ob-gyn doctors follow a "when in doubt, cut it out" philosophy, which encourages $\mathrm{C}$-sections whenever the doctor has any concerns that a vaginal delivery may threaten the health of an infant" [34]. Diminution of obstetric services on high-risk pregnant women in order to eliminate the possibility of litigation would be detrimental to expecting mothers, especially low-income patients and those living in rural areas who had little option but to rely on available public health care institution. Such practices would defeat the basic and actual purpose of practicing medicine in the first place and consequently, had negative impact on the quality health care of the population as a whole.

\section{References}

[1] Association of American Medical Colleges. Obstetrics and Gynecology: Overview. https://www.aamc.org/cim/specialty/list/us/336850/obstetrics_and_gynecology.html.

[2] Chandraharan E,Arulkumaran S. Medico-legal problems in obstetrics. Current Obstetrics \& Gynaecology 2006; 16:206-210. http://dx.doi.org/10.1016/j.curobgyn.2006.05.003.

[3] Franklin WP, Williamson WW. Bad Baby Lawsuits: Defending Brain-Damaged-Infant Claims. The Brief 1993; 22: 55-64.

[4] CRICO Strategies. Annual Benchmarking Report: Malpractice Risks in Obstetrics, 2010, Cambridge. http://www.rmfstrategies.com/ /media/Files/Strategies/Reports/2010_annual_benchmark.pdf.

[5] The American Congress of Obstetricians and Gynecologists. Medical Liability Climate Hurts Patients and Ob-Gyns: Survey Reveals $\begin{array}{llllll}\text { Continuing Trend. ACOG Release 2012, } & \text { September }\end{array}$ http://www.acog.org/About_ACOG/News_Room/News_Releases/2012/Medical_Liability_Climate_Hurts_Patients_and_Ob-Gyns.

[6] Seattle Children's Hospital Research Foundation. Airway, Breathing and Lung Conditions: Birth Asphyxia. http://www.seattlechildrens.org/medical-conditions/airway/birth-asphyxia/.

[7] Jasper P, Arulkumaran S. Perinatal Asphyxia: An Overview. In: Arulkumaran S, Jenkins HML, Editors. Perinatal Asphyxia. Chennai, India: Orient Longman Ltd; 2000, 1-20.

[8] Hankins DV, Koen S, Gei AF, Lopez SM, Van Hook JW, Anderson GD. Neonatal organ system injury in acute birth asphyxia sufficient to result in neonatal encephalopathy. Obstet Gynecol 2002; 99: 688-691. http://dx.doi.org/10.1016/S0029-7844(02)01959-2.

[9] Spector JM, Daga S. Preventing those so-called stillbirth. Bulletin of the World Health Organization 2008; 86, 4: 241-320. http://dx.doi.org/10.2471/BLT.07.049924.

[10] Leigh S, Granby P, Turner M, Wieteska S, Haycox A, Collins B. The incidence and implications of cerebral palsy following potentially avoidable obstetric complications: a preliminary burden of disease study. BJOG 2014; 121: 1720-1728. http://dx.doi.org/10.1111/14710528.12897.

[11] Cavanaugh MA. Bad cures for bad babies: policy challenges to the statutory removal of the common law claim for birth-related neurological injuries. Case Western Reserve Law Review 1993; 43, 4: 1299.

[12] Royal College of Obstetricians and Gynaecologists. Shoulder Dystocia. RCOG Green-top Guideline No. 42, 2012. http://www.rcog.org.uk/files/rcog-corp/GTG42_25112013.pdf.

[13] Lerner H. Shoulder dystocia: facts, evidence, and conclusions. Shoulder Dystocia Info, 2004. http://www.shoulderdystociainfo.com/shoulder_dystocia.htm.

[14] Duff DG. Compensation for neurologically impaired infants: medical no-fault in Virginia. Harvard Journal on Legislation 1990; 27, 2: 391452, at p. 394.

[15] Talic A, Honemeyer U. Cerebral Palsy: state of art. Donald School Journal of Ultrasound in Obstetrics and Gynecology 2010; 4, 2: 189-198, at p. 189.

[16] Gibson CS, Maclennan AH, Goldwater PN, Dekker GA. The antenatal causes of Cerebral Palsy: genetic and viral associations. Fetal and Maternal Medicine Review 2008; 19, 3:181-201, at p. 182.

[17] National Institute of Neurological Disorders and Stroke. Cerebral Palsy: hope through research. http://www.ninds.nih.gov/disorders/cerebral_palsy/detail_cerebral_palsy.htm.

[18] Sieradzki DL. Throwing out the baby with the bathwater: reforming the system for compensation obstetric accidents. Yale Law \& Policy Review 1989; 7, 2: 538-566. 
[19] Cavanaugh MA. Bad cures for bad babies: policy challenges to the statutory removal of the common law claim for birth-related neurological injuries. Case Western Reserve Law Review 1993; 43, 4: 1299.

[20] Minkoff H. Fear of litigation and caesarean section rates. Seminars in Perinatology 2012; 36, 5: 390-4. http://dx.doi.org/10.1053/j.semperi.2012.04.025.

[21] Apfel D. Clinical markers establishing a causal relationship between birth asphyxia and Cerebral Palsy: A primer for trial lawyers. American Journal of Trial Advocacy 1997; 21, 1: 1-66.

[22] NHS Litigation Authority. Ten years of maternity claims: An analysis of NHS litigation authority data. London, United Kingdom: NHS Litigation $\quad$ Authority; 2012. http://www.nhsla.com/safety/Documents/Ten\%20Years\%20of\%20Maternity\%20Claims\%20\%20An\%20Analysis\%20of\%20the\%20NHS\%20LA\%20Data\%20-\%20October\%202012.pdf.

[23] Berglund S, Grunewald C, Pettersson H, Cnattingius S. Severe asphyxia due to delivery-related malpractice in Sweden 1990-2005. An International Journal of Obstetrics and Gynaecology, 2008; 115: 316-323. http://dx.doi.org/10.1111/j.1471-0528.2007.01602.x.

[24] Moore PJ, Adler NE, Robertson PA. Medical malpractice: the effect of doctor-patient relations on medical patient perceptions and malpractice intentions. Western Journal of Medicine, 2000; 173: 244-250. http://www.drmed.org/medical_errors/pdf/medical_malpractice.pdf. http://dx.doi.org/10.1136/ewjm.173.4.244.

[25] AndersonD, Dumont S, JacobsP, Azzaria L. The personal costs of caring for a child with a disability: A review of the literature. Public Health Reports 2007; 122, 1: 3-16.

[26] Centers for Disease Control and Prevention. Economic Costs Associated with Mental Retardation, Cerebral Palsy, Hearing Loss, and Vision Impairment - United States, 2003. The Morbidity and Mortality Weekly Report 2004; 53: 5759.http://www.cdc.gov/mmwr/preview/mmwrhtml/mm5303a4.htm.

[27] Eddy LL, Engel JM. The impact of child disability type on the family. Rehabilitation Nursing, 2008; 33,3: 98-103. http://www.rehabnurse.org/pdf/rnj287.pdf. http://dx.doi.org/10.1002/j.2048-7940.2008.tb00212.x.

[28] Reichman NE, Corman H, Noonan K. Impact of Child Disability on the Family. Maternal and Child Health Journal $2008 ; 12$, 6: 679-683. http://www.medscape.com/viewarticle/581577_2. http://dx.doi.org/10.1007/s10995-007-0307-z.

[29] Sajedi F, Alizad V, Malekkhosravi G, Karimlou M, Vameghi R. Depression in mothers of children with Cerebral Palsy and its relation to severity and type of Cerebral Palsy. Acta Medica Iranica 2010; 48, 4: 250-254.

[30] Manuel J, Naughton MJ, Balkrishnan R, Smith BP, Koman LA. Stress and adaptation in mothers of children with Cerebral Palsy. Journal of Pediatric Psychology 2003; 28, 3: 197-201. ‥ http://jpepsy.oxfordjournals.org/content/28/3/197.full.pdf+html. http://dx.doi.org/10.1093/jpepsy/jsg007.

[31] Wenstein SL. Medical Liability Reform Crisis 2008. Clinical Orthopaedics and Related Research 2009; 467, 2: 392-401. http://dx.doi.org/10.1007/s11999-008-0603-y.

[32] Bobbitt JD, O'Connor MK, Easley HA. North Carolina's proposed birth-related neurological impairment act: A provocative alternative. Wake Forest Law Review 1991; 26, 4:837-878.

[33] Klagholz J, Strunk A. Overview of the 2012 ACOG Survey on Professional Liability. The American College of Obstetrics and Gynecology, 2012 .

https://www.acog.org/About_ACOG/ACOG_Departments/Professional_Liability/ /media/Departments/Professional\%20Liability/2012PLSur veyNational.pdf. [34] Kim B. The impact of malpractice risk on the use of obstetrics procedures. Journal of Legal Studies 2007; 36 : 79-116. http://dx.doi.org/10.1086/520069. 